\title{
Does E-Reading Enhance Reading Fluency?
}

\author{
Rahima S. Akbar ${ }^{1}$, Hanan A. Taqi ${ }^{1}$, Abdulmohsin A. Dashti ${ }^{1} \&$ Taiba M. Sadeq ${ }^{1}$ \\ ${ }^{1}$ The English Department, College of Basic Education, Ardhyia, Kuwait \\ Correspondence: Rahima S. Akbar, The English Department, College of Basic Education, Ardhyia, Kuwait. \\ E-mail: rahima64@yahoo.com
}

Received: February 4, 2015 Accepted: March 9, 2015 Online Published: April 23, 2015

doi:10.5539/elt.v8n5p195 URL: http://dx.doi.org/10.5539/elt.v8n5p195

\begin{abstract}
Extensive reading is reading as much as possible, for one's own pleasure, at a difficulty level at which one can read smoothly and quickly. In the domain of reading, this paper investigates the effect of extensive reading from e-books, through utilizing a number of downloadable reading application programs on the students' e-devices, as opposed to traditional book-reading in an ESL context. It aims at providing answers as to how e-book reading affects the students' reading rate, their reading comprehension, and their attitudes to reading. A group of 40 freshman female students studying in the College of Basic Education, in the English Department participated in the study. Students' writing diaries together with two questionnaires made up the tools of the study. The data was analyzed both quantitatively and qualitatively. The findings indicate that e-reading may accelerate the progress of the students' reading rate, which might be due to the utilization of the reading application features that trains the students to practice faster rates of reading. As for the comprehension level, the students reported lower levels when they read from an e-resource. On the other hand, the students' attitudes towards e-reading tend to be less positive when compared to conventional book reading, due to a number of extraneous factors that were not part of the inherent nature of the e-reading activity. Future studies on e-reading, whereby confounding factors will be rigorously controlled for are highly recommended to reach out more conclusive findings on the matter.
\end{abstract}

Keywords: reading efficacy, extensive reading, e-reading, reading applications, book-reading, reading rate, reading comprehension, attitudes to reading

\section{Introduction}

Reading is a skill that involves two essential processes; a conscious process where the reader focuses on textual information (top-down mode), and an unconscious process in which the reader focuses primarily on his/her background knowledge and prior experience that are mentally organized in the brain of the learner as categories (bottom-up mode) (Kintsch \& Van Dijk, 1978). Both processes take place in the brain of the reader continuously and simultaneously until the reader reaches a satisfying level of comprehension. A distinction between extensive and intensive reading (slow and careful reading) was demonstrated by Yamashita (2013) who states that in extensive reading, students read simpler materials where a detailed understanding of the reading material is not required. Richards and Schmidt (2002) explain that the main purpose of this type of reading is to develop good reading habits, build up knowledge of vocabulary and structure, and promote a positive attitude towards reading in general.

In this study, we focus on extensive reading, a reading that was described as being "a highly individualized approach to reading improvement... whereby students select their books and read them at their pace" (Mikulecky, 2008, p. 3). The benefits of such type of reading has been documented by Day and Bamford (1998), including developing a positive attitude towards SL reading as students are given the chance to read what they like, and in accordance to their own pace, motivating the students to want to read more; hence, increasing the readers' fluency (comprehension) and rate (how fast they read). The two aspects of reading fluency were substantially examined in previous research, yet with the focus being more on oral reading than silent reading (e.g., Fuchs et al., 2001), and mostly concentrating on either rate or fluency, but not both at a time.

As we are living in a world that is going extremely mobile, with portable devices that can fit into our pockets, to connect us to a tremendous sources of information and enable us to communicate almost everywhere we go, we believe it is getting extremely essential for the researchers to investigate the efficiency of reading when reading 
from an e-resource.

Therefore, the current study will investigate the effect of extensive reading from e-books as opposed to traditional book reading. We will focus on two aspects of reading: fluency (rate and comprehension), and attitudes. Based on empirical evidence, our aim is to provide answers to three main questions; in particular, our main goal is to find out which medium of reading would be more efficient in boosting readers' rate of reading, comprehension levels, and the establishment of positive attitudes toward reading in a language other than the native language of the reader. Hence, our study seeks answers for the subsequent questions:

1) How does e-book reading affect the students' reading rate?

2) How does e-book reading affect the students' reading fluency?

3) How does e-book reading affect the students' attitudes to reading?

In the process, a brief review of literature discussing a number of related issues will be displayed.

\section{Review of Literature}

\subsection{The Importance of Teaching Reading in Second Language Learning}

Many researchers in second language learning arena claim that 'simply reading' is the most effective way of acquiring vocabulary (such as Krashen, 1993; Hulstijn, 1998; Zahar, Cobb, \& Spada, 2001). Krashen (1993) for example, claims that reading is an effective way of building up language competence as it is the most useful method of vocabulary learning. Others were a little conservative in this regard, Hulstijn (1998) for example, agrees on the significance of reading in vocabulary building. Yet he suggests that reading should be accompanied by other activities that promote intentional vocabulary learning. Further, Zahar, Cobb, and Spada (2001) support Hulstijn in this essence, and they recommend providing a second language learner with a well-balanced language program that presents incidental vocabulary learning through the means of reading and intentional vocabulary learning by the means of other learning activities. However, Pigada and Schmitt (2006) challenge the previous claim to question the amount of learned vocabulary through the means of reading. They claim that such studies seem to ignore 'partial learning' of words. Upon their examination of the words learned during an extensive reading session for a month, they concluded that the learners' knowledge of around $65 \%$ of the target words spelling, meaning or grammatical features were developed and at various levels.

\subsection{Extensive or Intensive Reading, Oral or Silent Reading}

Researchers have distinguished between two modes of reading, intensive and extensive. While the former introduces a reading material with the objective of detailed understanding of the full text, the latter presents simpler material with the objective being developing positive attitudes towards reading, and building up the target language competence.

Leung (2002), who utilizes learners' diaries and private tutorial sessions, presents an important benefit of extensive reading programs that found that students may avoid reading because they find it challenging to find time, discipline and commitment to start reading. However, once they are given the chance to establish the habit of reading, it may become part of their daily activities. The outcome will eventually lead the learner to gain an intrinsic motivation, a type of motivation that will drive the learner to produce a much more creative work when compared to gaining an extrinsic motivation, sustained effort, and feel less anxious in the case of failure in achieving the required goal (Ryan \& Delci, 2000).

On the same issue, a survey was conducted by NFER institution to identify intrinsic motivation. They defined it as being 'the form of a positive self-concept as a reader, a desire ...to read and a reported enjoyment...in reading', to be at the core of attitudes to reading (NFER survey, 2007, p. 2). Further, the survey report explained that such interest in reading may be obtained when students are given the chance to read stories from which the readers may develop a deeper understanding of human behavior (Benton \& Fox, 1985) through involving the readers in books that will develop their personal and social attributes besides developing their reading abilities. The survey reports a leveling off of the decline in positive attitudes and self-confidence in reading amongst British children between the years 2003 and 2007, compared to the steep decline in positive attitudes to reading between 1998 and 2003. The reasons for the occurring pattern were not directly investigated, yet a very important point was raised in the report concerning the lack of evidence about on-screen reading, an issue that became a major limitation amongst the new generation moving towards e-reading during a large part of their lives. At this point, types of reading needed further investigation.

Differences between silent reading and oral reading were identified by Hiebert, Wilson, and Training (2014). In oral reading, Hiebert, Wilson, and Training explain, the learner would not be able to 'gloss over' an unknown 
word as s/he can do in silent reading (p. 7); the reader will be constrained by his or her rate of talking; and the fact that the reading process is presented to an evaluator may suggest that a certain level of similarity may be presented in the way people read. On the other hand, silent reading is constrained by the limitation of what the brain and the eyes can do simultaneously. Fake self-reports of the reading rate is another constraint of silent reading if the readers' claim is not verified by comprehension assessment. As a result, research on silent reading seems to be even more abandoned among literacy researchers, with some being skeptical of the issue and others being disinterested (Brozo \& Johns, 1986; J. Cassidy \& D. Cassidy, 2009). Hiebert et al. suggest that using a digital assessment tool will overcome the skepticism associated with the data produced from investigation on silent reading. They, therefore, utilize the interactivity of the computer page to measure the students' comprehension and rate in silent reading 'reliably, frequently, and with authentic texts and tasks' (p. 11).

A third constraint which tends to affect silent reading more than oral reading is 'reading stamina' - the ability to maintain your attention on what you read across longer texts (Hiebert et al., 2014, p. 8). Rosen (2010) describes stamina to be particularly critical amongst the 'i-generation', who is overwhelmed by a huge amount of information in various modalities, and as a result, might face some difficulties in maintaining involvement with longer texts presented in a rigid 'fine print'.

\subsection{E-Reading vs. Conventional Book-Reading}

Dillon (1994) attributes the inconsistencies of the results on the differences between e-reading and conventional book reading to weaknesses in research methodologies. As a result, he tends to be in favor of rejecting any clear differences. On the other hand, studies on reading comprehension have failed to present any significant differences between both media (Mason et al., 2001; Mayes et al., 2001; Noyes \& Garland, 2003; van de Velde \& von Grunau, 2003; Bodmann \& Robinson, 2004; Garland \& Noyes, 2004). According to Dillon (1994), the consistency of the findings on the matter allows us to safely establish equal levels of comprehension to both media.

Gartner (2011) states that the extent to which technology is affecting learning should be further studied, as conventional books have no longer become the only source of information. With the e-books being cheaper, holding a component of annotation and social interaction, as well as being space and weight savers, researchers should direct their effort into finding out whether e-texts can enhance learning, Gartner adds. In this vein, Gartner investigates the effect of e-texts (mainly using I-pads) on reading comprehension and transfer. In his investigation, he assigned two groups of learners to two types of texts, traditional or e-text. His study reveals no difference in comprehension level, but a higher level of learning transfer among the e-text group. This could be due to e-readers being able to scroll through bits of each page rather than look into the whole page, allow access to key words instead of wasting time to look them up in a dictionary, and as a result gaining the advantage of not wasting the reader's working memory on scanning the text for key words, he explains. He therefore concludes that learning may be enhanced by e-reading devices.

\section{Research Methods}

\subsection{Participants}

A group of 40 freshman female students, who were enrolled in a reading course in the English department at the college of Basic Education, participated in the study. For the course, the students used a textbook for in-class intensive reading, and chose stories for extensive reading done at home at a regular period (with the minimum of three reading sessions a week). The sessions were also recommended by the author of the book as part of the reading for pleasure component.

At the beginning of the semester, the students were offered a selection of stories across three levels of reading abilities; beginner, intermediate and advanced, as were listed in their assigned course textbook. They were instructed to make an initial choice based on their own perspective of their reading ability, download the book online and read through a full text page to find out the number of unknown key words. A maximum of five of unknown key words indicated that the book might be too difficult for their level and should therefore try a lower level book. Once they found the book that appeals to them, the students were required to read the book regularly and for more prolonged sessions as they progress in their reading. The procedure was applied for the first four weeks of the semester. The students were then requested to answer the questions in questionnaire 1, in which they were asked to reflect on conventional book reading.

This was followed by a four week extensive reading session, during which the students were required to read from a reading app downloaded on their smart phones, i-pads or galaxy tabs. Different reading apps were experimented by the students and they were given the choice of what to use in order to facilitate the students' 
comfort. This was an important dimension of reading to fulfill as the extensive reading task requires longer and more frequent sessions of reading as opposed to intensive reading. The apps claim that they enable the reader to read faster, allowing them to save time, be more productive and enjoy their reading time. A key difference between the reading app and the conventional text reading is the way the app trains the readers to use guided reading; whereby the reader is guided through the movement of highlights to expand the reader's number of words in a single fixation, comprehend groups of words more quickly, and move through the text more efficiently without distraction or back tracking, as our eyes are naturally attracted to movements rather than fixed images. The idea tends to mimic the speed-reading techniques whereby the reader is advised to move his finger across chunks of words on a page. The programmers of these apps claim that their programs make the technique even more efficient as the reader has the choice of changing the number of chunks in a line, and the frequency of eye fixation between lines. The students were given two training sessions on how to use the app in class. At the end of the two training sessions, the students started using one of the three reading apps: Speed Reading Trainer, Quick Reader or Read Race. The features of the three apps are ultimately similar. In the quick reader app for example, the reader can adjust the words per minute, guide stops between one or more stops per line or one or more lines per stop, in accordance to the reader's reading speed. The page presentation can be enhanced by choosing features that would allow the user to select from a number of guide styles, choose among thousands of text colors of the font or the background page, font size and line spacing. A normal reading icon takes the user to the pages from which the reader can read as if $\mathrm{s} / \mathrm{he}$ is reading from a book, just as it is the case with reading from any e-book. A speed reading test icon will tell the reader how fast the user reads. Rotating the device will allow the user to get a landscape image, with a wider page. The user can also navigate the app to find another chapter in the book or choose another book. As for unknown key vocabulary, the students were advised to find the meaning through context. If they failed to understand the text, they can use their e-reader device to look it up using another app (Vocab Wordology). The app will enable them to understand the meaning while they are on the same device, an action that might lessen the distraction caused by moving back and forth between two objects; a dictionary and a book.

The data of the study was collected through three main methods:

a) A Questionnaire was used to find out the students' attitudes to the reading from a conventional resource (books), progress in reading rate and comprehension levels. This was done by the end of the four-week conventional book reading. The questionnaire aimed to elicit the students' attitudes towards reading, the level of difficulty they encountered (in terms of reading rate and fluency), and the problems they experienced. A second questionnaire was used to elicit the students' responses to reading from an e-resource (app reading) by the end of the second four-week reading sessions. Some of the questions on the second questionnaire were changed to conform to the nature of e-reading in general, as well as the app reading in particular.

b) In order to gain a deeper insight into the students' perception of the new app reading tool, and to ensure the students were fully engaged in the required reading sessions, a WhatsApp group was formed during which the students presented their feedback on the performed reading sessions. Two sessions per week were done, in which each student discussed the level of difficulty, level of enjoyment and the main problems they encountered. This method was used to overcome the problem of face-to-face discussion as some students might not reveal their genuine emotions as a result of the student being placed in a distress atmosphere and lower their anxiety level.

c) The students were also required to fill in a reading rate sheet in which they pinpointed their reading rate in each reading session they performed. A manual procedure for finding their reading rate has been obtained from the students' course book for the purpose. They were also asked to keep a diary of what they read, in which they were required to write an overview of what they read, the time they spent, the number of pages they finished, and whether they liked or disliked what the new experience of reading from the app. A diary study "is a first-person account of a language learning... documented through regular candid entries... and then analysed for recurring patterns" (Bailey, 1990, p. 215). The tool is utilized as an important introspective tool in language research as it reveals the hidden learners' perspective that might not be uncovered through regular observational tools. Although diary studies might be distorted by subjectivity (Schmidt \& Frota, 1986), Jones (1994) claims that such feature should be considered as an important part of the study as it reflects on the importance of certain issues for diarists. Each student was therefore asked to hand in her reading diary by the end of the semester. The tool was used to validate and explain the results obtained by the other two tools (questionnaires and what's app chats).

In order to ensure the authenticity of the participants' responses, the students were assured that their responses in no way would affect their grades. Furthermore, the students were informed that it is the efficiency of the students' contribution, rather than the content, which will be counted for the grade. 


\subsection{Students' Diaries}

The students' diaries were analysed to find out their reflection on the following aspects:

a) Reading comprehension level of the read material

The issue was revealed through the students 'review of what they read. For the sake of analysis, the review was considered to be highly well-written if it included all the reviewing aspects they were instructed to include (title, author, main characters, general idea about the book, essential details, a closure), satisfactorily written, if it included the main aspects of the review (title, author, main characters, general idea), yet they missed essential details and/or closure, poorly written in case the diary has only included the book title, author, and main characters, but no presentation of the book's general idea, essential details and closure.

b) Frequency of reading

The number of reading sessions and the time spent on each reading session were also analysed. Frequency of app reading was anlaysed against the students' progress of reading rate and improved attitudes towards app reading.

c) Advantages of app reading vs. book reading

Students' reflection on the advantages of app/book reading was analyzed for recurrent patterns.

d) Problems encountered during app vs. book reading

Students' diaries were also analyzed to find recurrent patterns of any problems the students faced during app/book reading sessions, alongside any techniques they utilized to resolve such issues.

e) A reading rate progress graph was analyzed to find out whether the students have gone through a steady progress in their reading rate, declined reading rate, or a fluctuating reading rate. This was obtained manually using a procedure recommended in the students' textbook during book reading, and digitally using an app feature. Screen captures of each student's reading rate per session were also used to verify such claims during app reading sessions.

\section{The Study's Findings}

\subsection{Findings from Diaries}

Unfortunately, only two thirds of our sample has followed the instructions on how to write a diary during the app reading. Yet, some very helpful findings came out from this method of data collection. These might be summarized in the following

a) Students who presented highly to satisfactorily review of what they read in the app have shown positive reactions towards the experience alongside fluctuating to steadily improved reading rate. On the other hand, poorly reviewed accounts were mostly associated with a negative attitude toward the app usage. Their reading rate graph charts have also indicated a tendency of dropping to lower numbers of words per minute towards the last two weeks of app reading session. When examining the students' accounts on book reading, no similar patterns were identified, yet the majority of the students stated that reading from a book made them feel more relaxed, and less stressed out.

b) The students stated a number of problems they encountered during the app/book reading sessions, which included:

1) Fluctuating/declined reading rate: Around $80 \%$ of our sample stated their frustration for what they referred to as an unexpected declined or fluctuated reading rate as they progressed in reading. They claimed that as they felt their ability to understand what they read was getting better, their pace of reading was getting slower.

2) Unknown key words: Almost half of the sample (18 out of $40=45 \%$ ) complained about difficult words that made the reading material incomprehensible. The problem slowed them down, as they stated, and cut down their interest in what they read. Many of them stated that they resolved the problem by using another app (Wordology) on the same device. Two of the students added that constant app reading has made the problem less intense as they started to learn how to guess the meaning out of context. The same problem has also been indicated by the participants during the book reading sessions, with 16 out of 40 (comprising $40 \%$ of the sample) claiming that not knowing key words meaning was a major problem they faced. Around $69 \%$ of them felt that the act of using a dictionary has negatively affected their progress reading rate, and for many times resulted in a fluctuating reading rates during book reading sessions. As the problem was sorted out by using another feature on the same device during app reading, many of the students claimed that unknown vocabulary hasn't affected their reading rate progress. However, a higher number of learnt vocabulary was reported by $32 \%$ of the students in the book reading over app reading, with the students claiming that looking up a word in a conventional dictionary helps to 
better maintain it in their memory as opposed using a digital resource.

3) Boring book: $37.5 \%$ claimed that lack of enjoyment in app reading was a result of the nature of the book. In fact, the majority of those with such a claim stated that it was their fault as they didn't choose the right book. Others have put the blame on the app as it doesn't offer a wide selection of appropriate reading materials. As for book reading, only $5 \%$ stated a similar problem, and almost all the students claimed that they had a wider choice for finding an appropriate book. Hence, we may state that a large percentage of our sample didn't enjoy app reading due to the nature of the book rather than an intrinsic feature of the e-reading.

4) Eye-sight annoyance: Around $32.5 \%$ claimed that app reading has (or may develop) a negative effect on their eye sight as a result of staring at a small lighted screen for long period of time. The problem was claimed to partially resolve by a few of them after using a device with a bigger screen (I-pads for example). Two of the participants have also mentioned that app reading has incurred headache. This very issue of headaches has emphasized the perceived benefit of the absence of an irritating medium in the book reading. In other words, if not for the experience of app reading, the students may well not have realized this advantage in book reading.

5) Hated screen reading: $27.5 \%$ referred their lack of enjoyment in app reading to the fact that they always hated screen reading. On the other hand, $30 \%$ of the students stated that they hate reading from a book as it reminds them of studying.

6) Technical problems: being a new experience that may require constant practice, around $27 \%$ claimed that their lack of experience in using the app application has resulted in a general lack of enjoyment in app reading. Many of them added that the problem has become less effective towards the end of the app reading session. Some have also claimed that watching the demo for several times has raised their interest in app reading. Book reading on the other hand, tends to initiate less stress as it doesn't require any technical skills. As a result, around $79 \%$ of the participants find book reading as more relaxing and enjoyable.

7) Limited existing variety of books: Around $10 \%$ of the students claimed that they couldn't find enough choices of books in the free app. Those who downloaded the full version were able to resolve that problem.

8) Lack of screen reading stamina and limited free time were also mentioned by $5 \%$ of the students. When the students experienced book reading, $15 \%$ of the participants claimed that one of the advantages of book reading is that it increases their reading stamina. The issue has resulted in getting the students to read for longer periods of time compared to app reading. An average of 45 minutes of app reading in each session as opposed to 75 minutes of book reading has been reported by the students.

\subsection{Findings from the Questionnaires}

The first focus of the paper was on the effect of e-book reading on the students' reading rate. While the statistics show that the students started with a lower book reading rate than the e-book rate (mean $=134.1$ ); when they finished, the e-book reading rate become slightly higher than book reading. It appears that both paper book and e-book reading rates have increased by an average of 15.2 and 37.8 seconds consecutively (See Figures $1 \& 2$ ).

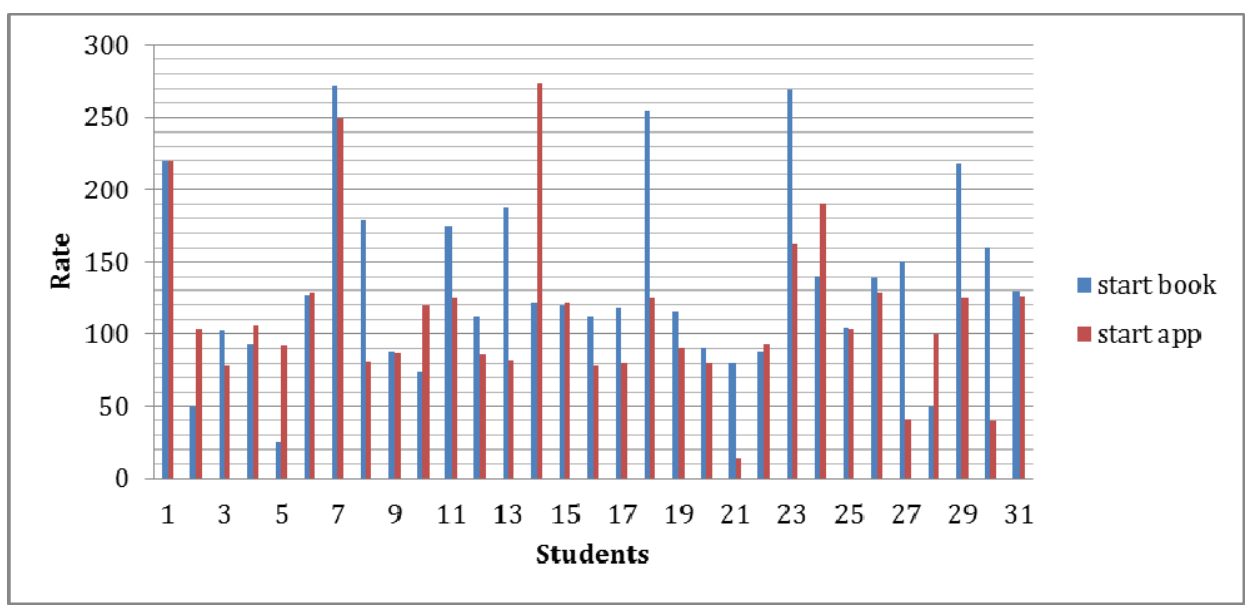

Figure 1. The start rates of paper book versus e-book reading in seconds 


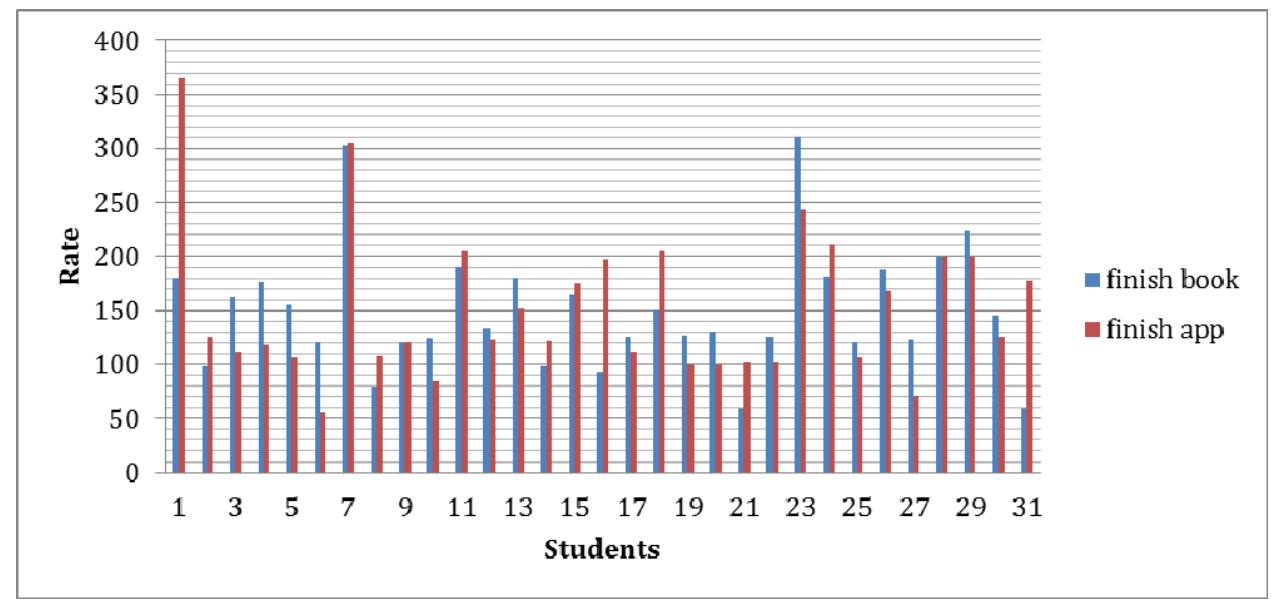

Figure 2. The finish rates of paper book versus e-book reading in seconds

In a one-way ANOVA by frequency of reading in English, high significance was found in both the start and finish rate of e-book reading. Astonishingly, the significance was found to be a result of those who stated they have never read in English obtaining the lowest average of the start and finish rates (55.5 and 101.0 seconds successively). In addition, the participants who believe they frequently read in English spent more time reading, where their average reading start and finish rates were 178.2 and 240.8 seconds consecutively.

The rate of reading is mostly affected by the fluency problems the students face while reading, especially that the reading is not in their native language (Arabic). While reading from a paper book, the majority of the students agree that they understand the vocabulary, or find the British/American expressions difficult. In conducting several one-way ANOVA tests by age by frequency of reading in Arabic by having a device and by the frequency of using the device, high significance was found $(0.019,0.047,0.041 \& 0.024)$. Similar results were found when reading from an e-book, yet no significance was found. However, it was found that despite the fact $40.6 \%$ of the participants do not lose their focus while reading from a paper book, $47.9 \%$ believe that their minds drift off when reading from an e-book. In conducting two T-Tests by the frequency of reading in Arabic and the frequency of reading in English for both paper book reading and e-reading, significance was found for paper book reading at $p=0.035$, and significance was found at 0.033 , where in both cases the students who never read either English or Arabic could concentrate the least.

Attitudes towards e-book vs. paper-book reading were mainly obtained from the students' responses on a list of problems associated with each reading resource in the questionnaires (See Figures $3 \& 4$ ).

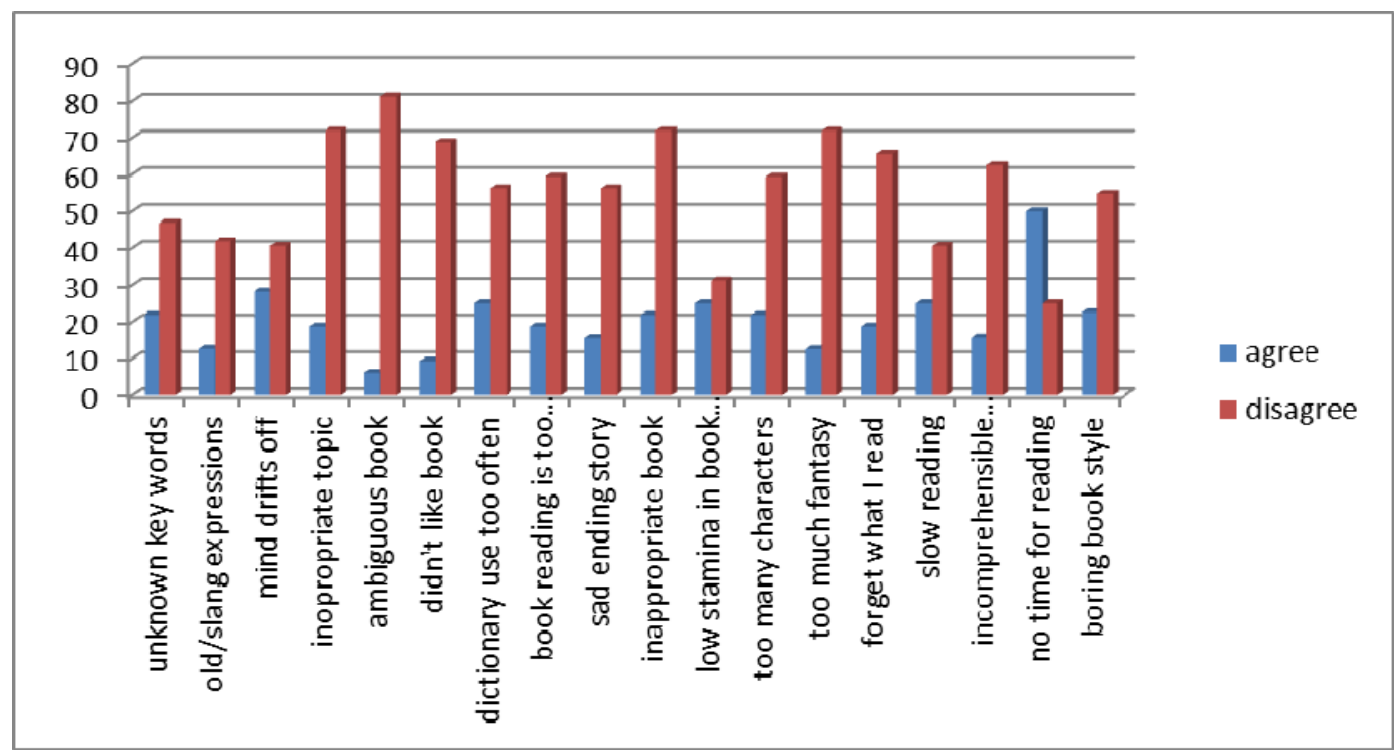

Figure 3. Problems associated with paper-book reading 


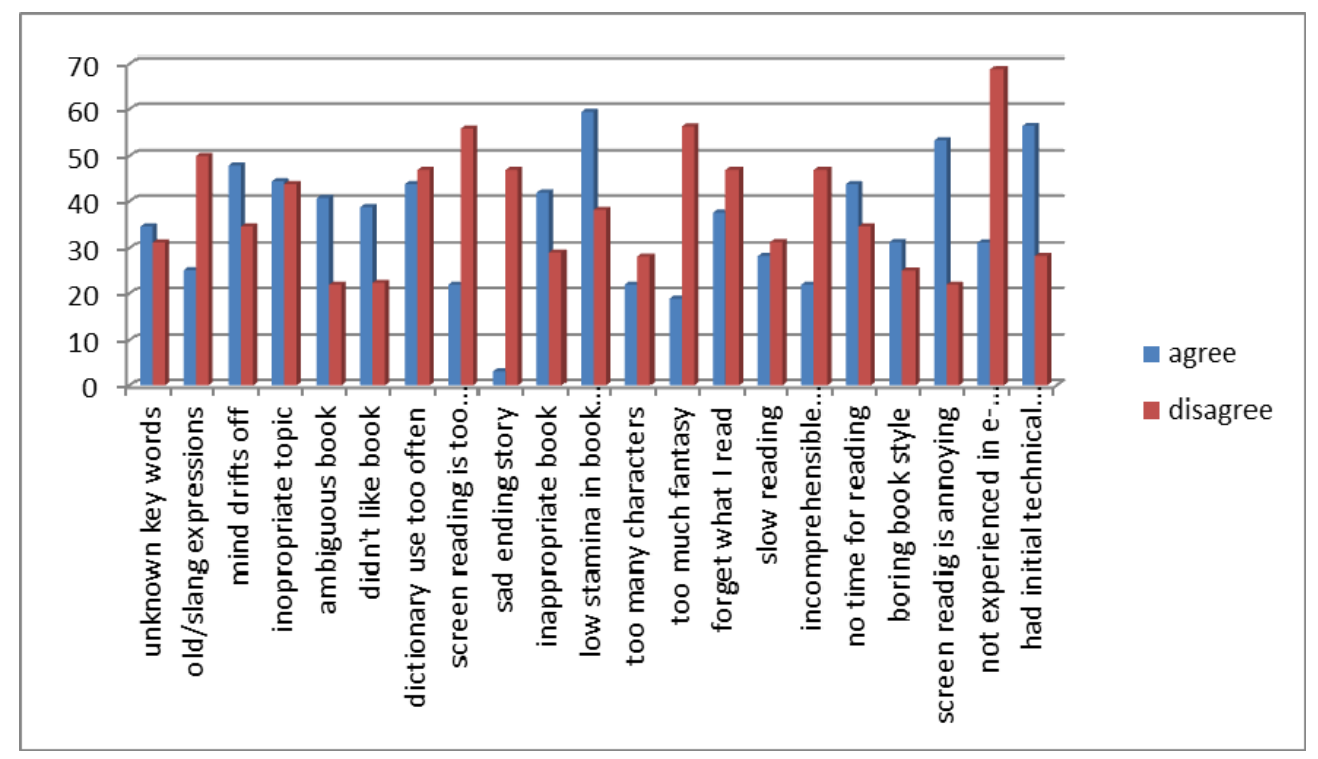

Figure 4. Problems associated with app reading

In this vein, most students reading from a paper book disagree that they lack background information about the topics of the book read, or that it is ambiguous and boring. High significance was found by the frequency in reading in English at $\mathrm{p}=0.044$ as the students who frequently read in English agreed least that they lack background information about the topic. On the other hand, while reading from the e-book, most students are neutral concerning the background and interest of topic, yet $65.7 \%$ find reading from a screen boring. Most students stated that the paper book was not ambiguous, while they reflected neutrality when e-reading. Significance by age, frequency of reading in Arabic and frequency of e-reading was found when interacting with the ambiguity of paper-book reading at $0.040,0.007,0.018$ and 0.027 . A two-way ANOVA by frequency of reading in Arabic by frequency of using an e-reader reflected significance of $p=0.027$, as the students who never read in Arabic and frequently use an e-reader disagree most that the content of the paper book is ambiguous. While both paper book reading and e-book reading was not found to have too much fantasy, e-book reading was found lacking stamina (59.4\%). High significance was found in relation to paper book reading and the amount of fantasy in the book (by frequency of reading in Arabic $p=0.046$. by frequency of reading in English $p=0.032$, and frequency in using an e-reading device $p=0.049$ ). In a T-test by frequency of reading in English and frequency in using an e-reading device, significance was found at $p=0.040$, as the students who frequently read in English and frequently use an e-reading device disagree most.

When reading a paper book, most participating students stated they do not forget information (65.5\%). Significance, in this respect, was found in several one-way ANOVAs by age, frequency of reading in Arabic and frequency in using an e-reading device. It was found that students over 30 years old and the students who never read in Arabic mostly disagree that they forget information, while the participants who frequently use an e-reading application agree most. In addition, $62.5 \%$ feel that they comprehend the content of the paper book, and hence, $54.8 \%$ did not face problems with the content. Paper book readers (50\%), more than e-book readers $(43.8 \%)$, believe that time management is the biggest problem that affects their reading. The majority of student participants also believed that they did not lack comprehension when reading from an e-book (46.9\%). Although $43.8 \%$ of the participants reflected neutrality when it came to the content interest, significance was highly reflected when this statement interacted with the independent variables of age, frequency of reading in both languages, and frequency of using the device. It appears that the oldest age group agrees most that the content is boring, while the participants who rarely read Arabic and never read English, and frequently use an e-reading device mostly disagree.

When the students were asked about issues they faced while using the application of the e-book, $53.1 \%$ stated that reading from a screen is annoying. Moreover, $68.8 \%$ do not think that they are good with electronic devices; therefore, many students (56.3\%) indicated that they have faced a few problems when using the application for the first few times.

It appears from the results above that the majority of students feel that they would perform better when reading 
from a paper book. Furthermore, many students feel bored reading from a screen and get distracted easily. The interest in reading, the content and in finding the time to read was generally higher when the readers read from a paper book rather than reading from an e-book.

The effect of e-reading on the students' attitudes is very clear. Whereas $62.5 \%$ of the students found reading in general satisfying, the majority were neutral when it came to e-book reading. In a one-way ANOVA by age, significance was found at $p=0.049$. This was found as a result of the fact that the participants over 30 years old were completely satisfied with paper book reading. Most participants enjoy reading paper books in Arabic and English, and $56.3 \%$ feel they comprehend the materiel read. A one-way ANOVA by age shows high significance of $p=0.040$, as the participants who are over 30 years old were mostly dissatisfied. As for the frequency in reading in English, a one-way ANOVA by frequency in reading in English shows significance of $p=0.032$ (as the students who frequently read in English were not satisfied). The paper book reading reflected neutral satisfaction of the rate of reading. Three one-way NOVA tests were conducted to find significance by age, frequency of English reading and the use of an e-reading device $(p=0.009, p=0.028, \& p=0.046$ successively) However, the majority of e-book readers were dissatisfied with the experience $(46.9 \%)$, and $68.7 \%$ reflected satisfaction when it came to reading rate satisfaction, yet $53.1 \%$ were not sure they comprehended what they read from the e-book. The adjustment benefits gained from the application fluctuated between $40.7 \%$ who felt satisfied, $25 \%$ who were neutral, and $34.4 \%$ who were not satisfied. In a closer look, a one-way ANOVA of high significance by age was found, as the participants over 30 years old did not think they benefited from the adjustments provided by the app.

\section{Discussion}

The current study aims to investigate the effect of extensive reading from e-books on the readers' pace of reading, level of comprehension, and attitudes towards reading. A comprehensive analysis of the students' diaries and what's app feedback, alongside the quantitative analysis of the questionnaires have been gauged to fulfill our research objectives.

Due to administrative problems at the beginning of the semester, the classes were delayed for two weeks. As a result, we decided to begin the app reading session before the book reading session to ensure having an ample time to practice using the app (due to anticipated technical problems from the students' first use of the app), especially as the students would usually stop coming to their classes during the final two weeks of the semester. The students were therefore exposed to app reading before book reading.

In order to fulfill our study's first objective, we examined the effect of app reading vs. book reading on the students' reading rate as indicated by our sample responses in the questionnaire. Along the same line, our findings indicate that the students have started at a slower pace when they read from an e-resource, but progressed much more rapidly to a faster pace when compared to book-reading (See fig 1). Bearing in mind that the students were exposed to digital reading before print reading, one may conclude that e-reading would probably lead to a more rapid progression in reading rate when compared to book reading. Unexpectedly, however, the students' reading pace was significantly faster for those who described themselves as being less frequent readers in English than those who described themselves as being more frequent readers. Such an unexpected finding can be explained by a finding that was obtained from the students' diaries, when over $80 \%$ of them have stated they were frustrated to find themselves getting slower as they progressed in reading and gained higher comprehension levels of what they read. This may indicate that our sample tends to trade reading speed to levels of comprehension, whereby the better level of understanding leads them to slow down their reading pace.

As for the effect of digital reading on the students' fluency (level of comprehension), the findings of the current study reveals that the majority of our students across different age groups seem to agree on gaining lower levels of comprehension during the app reading as opposed to book reading, regardless to whether they were frequent e-readers or book-readers. Looking back into the students reflections in their diaries, some have further justified the difficulties they encountered in comprehending what they read to the fact that they had a wider selection of books than app material. Besides, some of our students have related their ability to comprehend to the ability to remember what they read. As explained earlier, one of the findings was an association between enhanced memory and book reading, particularly amongst older students who haven't gained enough experience in e-reading.

The second part of the questionnaire has mainly been used to reflect on the students' attitudes towards reading English in general, and reading from a digital source vs. an e-source. The findings reveal a general satisfaction in book reading over e-reading, particularly amongst those who are above thirty years old, who tend to be even significantly more satisfied in book reading. The students have also revealed moderate satisfaction in their pace 
of reading during the book reading session. Conversely, around half of the students show complete dissatisfaction in their pace while they read from an e-book. Nevertheless, they were uncertain on whether they comprehended what they read from the app. Although a satisfying percentage of the participants evaluated the adjustment features as being beneficial (40\%), older students seem to believe that they have not benefitted from the features provided by the app. Bearing in mind that students who are above thirty years old have reported experiencing technical problems with e-device usage, the finding might have been a normal consequence of the lack of the overall knowledge in using e-devices.

An investigation of the problems the students faced, which have mainly led to negatively affect their reading rate, has shown that the students seem to have faced more problems during the app reading session when compared to book reading session, based on the statistical findings of $22 \%$ of the students agreeing with app reading problems listed in the questionnaire vs. 14\% only of those who agreed on the list of book reading problems (See Figure 5).
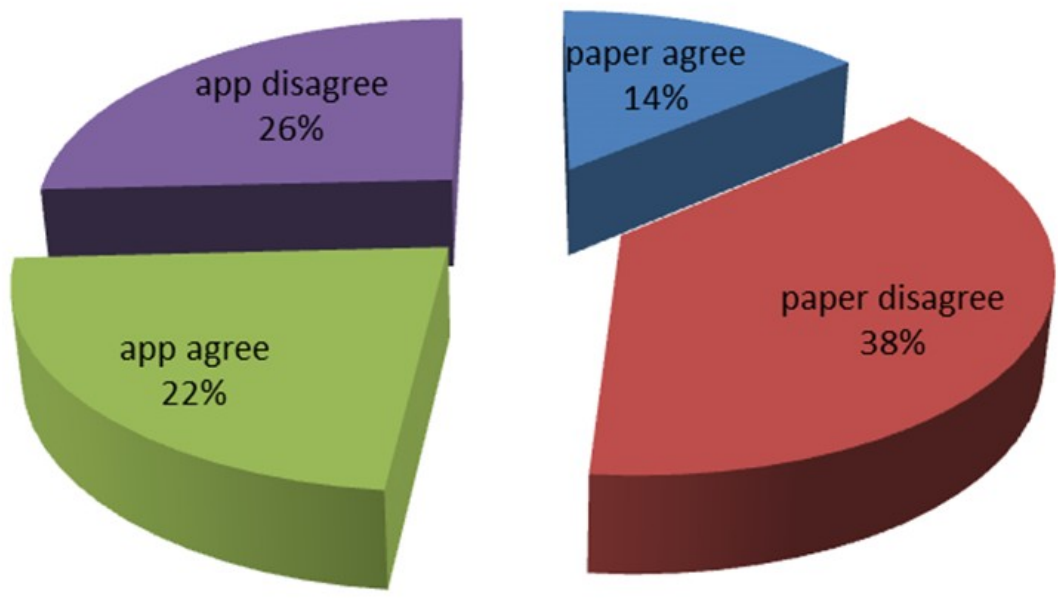

Figure 5. Students' book/app agreement/disagreement

The finding implies that the students felt less comfortable during app reading as opposed to book reading.

A thorough examination of the results obtained qualitatively and quantitatively in this regard has also pointed out to the following findings:

a) Time management seems to be one of the most agreed upon problem in book-reading by slightly more than half of the sample. The same problem has been reported by the students during the app reading, yet to a lesser extent (43\%). The finding has been justified by the students in their diaries when they mentioned that having their device with them wherever they go made the reading material more accessible from the app.

b) Our sample has also reported difficulty to concentrate (lack of stamina) to be a major problem. Yet, the problem tends to get significantly more intense when they read from an e-book compared to reading from a paper-book amongst the students who are not used to reading in general. Nevertheless, the same problem gets less prominent amongst those who describe themselves as being frequent e-device users and English frequent readers. The finding may pinpoint an important advantage of book-reading over e-reading, that is, that the readers may put up with more time of reading from a printed book when compared to reading from an e-resource.

c) Paper-book reading was associated with more enhanced memory by the majority of the students; especially amongst those whose age is above thirty. Frequent e-readers on the other hand, seem to reject such association. The finding may indicate that memory problems associated with e-reading seems to affect older students in particular. Moreover, once the students get used to reading from e-resources, the problem would gradually diminish.

d) Reading from an e-resource has been negatively perceived by around half of the sample as a result of annoying screen usage. The view has also been raised by a large number of the students in their diaries as explained earlier. Slightly above $50 \%$ of the students stated that lack of familiarity in using e-devices has initiated a few problems during the early stages of app reading. The issue has also been raised by around one 
third of the sample, who claimed they initially faced technical problems on app usage which were resolved later on with constant practice and watching the app demo. (The finding might indicate that exposure to e-reading programs will eventually enhance the distress associated with digital book reading).

e) Lack of background information and interest of the reading material topics seems to get less intense when the students read from a paper-book. Investigation of the students' diaries during the reading sessions has also indicated a similar trend, in which the majority of the sample stated that the app has narrowed down their choices to a less comprehensive selection compared to paper-reading, whereby they had a much wider range of books to choose from. This aspect in particular was due to the fact that the students didn't know how to preview the available selection from the app. (The finding suggests that the students' dissatisfaction in app reading was largely due to the content of the reading material rather than the source of reading).

\section{Conclusions}

After a thorough analysis of the current study's findings, previous studies on similar aspects of reading, and based on the triangulation of the multi-dimensional methods of data collection, one would safely reach out a number of conclusions:

Firstly, the findings of the study may falsely lead the reader to consider paper-books a better reading resource when compared to e-books. Yet, a closer look into the findings may reveal a number of advantages in exposing the students to e-reading over paper-book reading, which we summarize as follows:

1) Many of the problems the students associate with app reading were mainly related to a number of extraneous features of the app reading experience, such as lack of interest in the read material from the app alongside a number of technical issues, rather than the innate nature of e-reading. Hence, we may safely conclude that developing familiarity in e-reading will unravel a huge side of the distress the students experienced during e-reading.

2) When we consider our study's findings in relation to the effect of e-reading on the reader's pace of reading, we may also safely conclude that promoting the adoption of e-books by educators will train the new generation to read more and develop better reading rates if students learn how to benefit from the training features supplied by such digital applications.

3) E-books tend to be easily accessible; hence they may promote more time of reading, particularly when the reading material can be downloaded on the readers' smart devices. Educators may make a well use of such devices across the e-generation who habitually hold their devices with them almost whenever and wherever they go.

4) The advantage of better time management associated with e-reading over book-reading may well be exploited by educators. The finding implies that the problem of inadequate time for reading may well be resolved by offering e-reading within ESL reading curriculums.

5) When considering previous findings on the effect of providing information through a digital versus a print medium on long term memory (Akbar et al., 2013), which showed a quicker shift from 'remember' indicating a lower level of memory to 'know' signaling a higher level of memory, based on rigorous measures taken to control for confounding factors, we believe the students' claim of more enhanced memory associated with book-reading may require further investigation, especially as the actual memory of the read material has never been tested for in this research. We therefore recommend further researching on the aspect of better learning and remembering associated with book reading as claimed by the sample in the study.

Above all, our study establishes a number of main findings in relation to the research questions. Firstly, e-reading tends to better accelerate the readers' pace of reading progress when compared to conventional book-reading. On the other hand, the effect of e-reading on reading comprehension does not seem to be a positive one. The finding appears to contradict previous studies on a similar issue, revealing no difference in comprehension when the reader reads from a digital vs. print source (Dillon, 1992). However, when considering the fact that the students' actual comprehension levels were never investigated in this research, we call for further investigation on the issue, whereby the readers' subjectivity is overcome through utilizing tools to account for actual comprehension levels.

Secondly, had the study controlled for a number of confounding factors such as enabling the students to fully exploit the e-reading application, and providing the students with a wider selection of e-books, we might have safely demonstrated more assertive findings in relation to the students' attitudes to reading from an e-resource. It is worth mentioning at this point that the students described the app reading experience as an innovative method of reading (as elicited from their WhatsApp feedback). Nevertheless, such enjoyment tends to be distorted by the 
students' inability to put up with the technicalities of the app usage. Further investigation in the field of e-reading is highly recommended to reach out more conclusive findings. At this point, we'd like to emphasize that our study has never accounted for gender differences due to the fact that the study's entire sample comprised of female students only. We therefore recommend that similar investigations need to be replicated on male participants, in order to attain to such an important factor.

An important implication of the current study, is that educators should consider utilizing e-applications in the teaching and learning processes of college students, particularly within the discipline of foreign language learning. Nevertheless, integration of such technical tools would certainly require providing the users with the basic skills in using them.

\section{References}

Akbar, R., Al-Hashemi, A., Taqi, H., \& Sadiq, T. (2013). Efficacy of Learning: Digital Sources versus Print. Journal of Education and Practice, 4(8).

Benton, M., \& Fox, R. (1985). Teaching Literature 9-14. Oxford: Oxford University Press.

Bodmann, S. M., \& Robinson, D. H. (2004). Speed and performance differences among computer based and paper-pencil tests. Journal of Educational Computing Research, 31, 51-60. http://dx.doi.org/10.2190/GRQQ-YT0F-7LKB-F033

Brozo, W. G., \& Johns, J. L. (1986). A content and Critical Analysis of 40 Speed Reading Books. Journal of Reading, 30, 242-247.

Cassidy, J., \& Cassidy, D. (2009). What's hot, what's not for 2010. Reading Today, 27(3), 1, 8-9.

Coyne, M., Kame'enui, E., \& Simmons, D. (2001). Prevention and Intervention in Beginning Reading: Two Complex Systems. Learning Disabil Res Pract, 16(2), 62-73. http://dx.doi.org/10.1111/0938-8982.00008

Cushman, W. H. (1986). Reading from microfiche, VDT and the printed page. Human Factors, 28, 63-73.

Day, R., \& Bamford, J. (1998). Top Ten Principles for Teaching Extensive Reading. Reading in a Foreign Language, 14(2).

Dillon, A. (1992). Reading from paper versus screens: A critical review of the empirical literature. Ergonomics, 35, 1297-1326. http://dx.doi.org/10.1080/00140139208967394

Dillon, A. (1994). Designing Usable Electronic Text: Ergonomic Aspects of Human Information Usage. Taylor $\&$ Francis. London.

Fuchs, L. et al. (2001). Oral Reading Fluency as an Indicator of Reading Competence: A theoretical, empirical, and historical analysis. Scientific Studies of Reading, 5(3), 239-256. http://dx.doi.org/10.1207/S1532799X SSR0503_3

Gould, J. D. et al. (1987a). Reading is slower from CRT displays than the paper: Attempts to isolate a single-variable explanation. Human Factors, 29, 269-299.

Garland, K. J., \& Noyes, J. M. (2004). CRT monitors: Do they interfere with learning? Behaviour \& Information Technology, 23, 43-52. http://dx.doi.org/10.1080/01449290310001638504

Gould, J. D. et al. (1987b). Reading from CRT displays can be as fast as reading from paper. Human Factors, 29 , 497-517.

Haynes, M. (2001). Extensive reading in the second language classroom. Richard R. Day and Julian Bamford. New York: Cambridge University Press, 1998.

Hiebert, E. H., Wilson, K. M., \& Training, G. (2014). Are Students Really Reading in Independent Reading Contexts? An Examination of Comprehension-Based Silent Reading Rate. Text Project Article Series 2014. Santa Cruz, California: TextProject.

Hulstijn, J. (1998). Semantic-informational and formal processing principles in Processability Theory. Bilingualism, 1(1), 27-28. http://dx.doi.org/10.1017/S1366728998000054

Jones, F. R. (1994). The lone language learner: A diary study. System, 22(4), 441-454. http://dx.doi.org/10.1016/ 0346-251X(94)90001-9

Keenan, S. A. (1984). Effects of chunking and line length on reading efficiency. Visible Language, 18, 61-80.

Kintsch, W., \& van Dijk, T. (1978). Toward a model of text comprehension and production. Psychological Review, 85(5), 363-394. http://dx.doi.org/10.1037/0033-295X.85.5.363 
Krashen, S. (1993). The power of reading. Englewood, Colorado: Libraries Unlimited.

Leung, C. (2002). Extensive Reading and Language Learning: A Diary Study of a Beginning Learner of Japanese. Reading in a Foreign Language, 14(1).

Mason, B. J., Patry, M., \& Bernstein, D. J. (2001). An examination of the equivalence between non-adaptive computer-based and traditional testing. Journal of Educational Computing Research, 24, 29-39. http://dx.doi.org/10.2190/9EPM-B14R-XQWT-WVNL

Mayes, D. K., Sims, V. K., \& Koonce, J. M. (2001). Comprehension and workload differences for VDT and paper-based reading. International Journal of Industrial Ergonomics, 28, 367-378. http://dx.doi.org/10.1016/S0169-8141(01)00043-9

Mikulecky, B. (2008). Teaching Reading in a Second Language. ELT Journal, 65(1), 99-101.

Muter, P., \& Maurutto, P. (1991). Reading and skimming from computer screens and books: The paperless office revisited? Behaviour \& Information Technology, 10, 257-266. http://dx.doi.org/10.1080/01449299 108924288

Noyes, J. M., \& Garland, K. J. (2003). VDT versus paper-based text: Reply to Mayes, Sims and Koonce. International Journal of Industrial Ergonomics, 31, 411-423. http://dx.doi.org/10.1016/S0169-8141(03)00027-1

Oborne, D. J., \& Holton, D. (1988). Reading from screen versus paper: There is no difference. International Journal of Man-Machine Studies, 28, 1-9. http://dx.doi.org/10.1016/S0020-7373(88)80049-X

Pigada, M., \& Schmitt, N. (2006). Vocabulary Acquisition from Extensive Reading: A case study. Reading in a Foreign Language, 18(1).

Richards, J. C., \& Schmidt, R. (2002). Longman dictionary of language teaching and applied linguistics. Malasiya: Pearson Education.

Rosen, L. (2010). Rewired: Understanding the IGeneration and the Way They Learn. NY: Palgrave Macmillan.

Ryan, R. M., \& Deci, D. M. (2000). Self-determination theory and the facilitation of intrinsic motivation, social development, and well-being. American Psychologist, 55, 68-78. http://dx.doi.org/10.1037/0003-066X. 55.1 .68

Schmidt, R., \& Frota, S. N. (1986). Developing basic conversational ability in a second language: A case study of an adult learner of Portuguese. In R. R. Day (Ed.), Talking to learn: Conversation in second language acquisition (pp. 237-326). Rowley, MA: Newbury House. Schmidt.

Van De Velde, C., \& Von Gru“ nau, M. (2003). Tracking eye movements while reading: Printing press versus the cathode ray tube. In Proceeding of the 26th European conference on visual perception, ECVP 2003. Paris, France: ECVP, 107.

Wilkinson, R. T., \& Robinshaw, H. M. (1987). Proof-reading: VDU and paper text compared for speed, accuracy, and fatigue. Behaviour \& Information Technology, 6, 125-133. http://dx.doi.org/10.1080/014492987 08901822

Yamashita, J. (2013). Effects of extensive reading on reading attitudes in a foreign language. Reading in a Foreign Language, 25(2), 248-263.

Zahar, R., Cobb, T., \& Spada, N. (2001). Acquiring vocabulary through reading: Effects of frequency and contextual richness. Canadian Modern Language Review, 57(3), 541-572.

\section{Copyrights}

Copyright for this article is retained by the author(s), with first publication rights granted to the journal.

This is an open-access article distributed under the terms and conditions of the Creative Commons Attribution license (http://creativecommons.org/licenses/by/3.0/). 